\title{
NOTES ON ACANTHOTHRIPS.
}

\author{
BY H. J. FRANKLIN, B. S., AMHERST, MASS.
}

On the 9 th of September, 1903, five females and one male Acanthothrips magnafemoralis Hinds, were found under the loose bark of a sycamore tree near the college grounds. Since then, a large number of specimens have been found on the same tree. While I have not found them on other sycamores in the neighborhood, their numbers on this tree would seem to indicate that the sycamore is their food plant. It is possible, however, that they fed, during the summer, on plants near this tree and that they were simply preparing to hibernate under its bark.

Acanthothrips magnafemoralis was originally reported from Miami, Florida. Dr. Hinds gave a very good description of the male of this species from a single specimen and, since that time, no further account of the insect seems to have appeared and no description of the female has been published.

Female.-The female, although generally larger, more robust, and with a more swollen abdomen, closely resembles the male in most respects.

Length $2.28 \mathrm{~mm}$. (2.I to $2.7 \mathrm{~mm}$.) ; width of mesothorax $0.49 \mathrm{~mm}$. (0.47 to $0.5^{2} \mathrm{~mm}$.) Relative lengths of the segments of the antennae as follows:

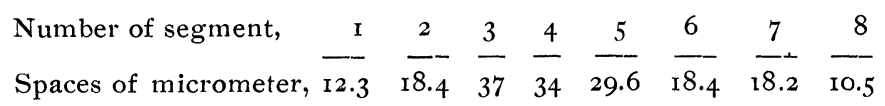

Described from nine specimens.

Two cotypes (two slides) have been deposited in the United States national museum. Three cotypes (two slides) have been deposited at the Massachusetts agricultural college. I have retained four cotypes (one slide).

The color of the male and female both is more or less tinged with red, as seen by transmitted light, owing to the presence of scattered hypodermal pigmentation. Fore femora strongly compressed; two apical segments of the antennae of both sexes with a straight, longitudinal row of about ten setae seen on the outer side of the segments above, when the antennae are anteriorly directed, beginning at the apex of the last segment; surface of the abdominal segments reticulated.

The description of this insect by reflected light is, in many respects, quite different from that by transmitted light.

By reflected light, the general color of the body above is seen to be light grayish tinged with red; the eyes and ocelli are brick-red in color; the last two segments of the abdomen before the tube are pale yellow and the outer two thirds of the tube is black. There is a dark brown, longitudinal, median basal stripe on the head above and the fore femora usually bear one or two isolated brown dots. A broad, 
Y-shaped, dark brown stripe begins on the mesothorax, crosses the metathorax, and extends on the dorsum of the abdomen to the posterior margin of the seventh segment. The base of the stripe is median on the dorsum of the abdomen and grows gradually wider anteriorly; it is narrowed between the segments. The arms of the $\mathrm{Y}$ nearly reach the anterior angles of the mesothorax. On the thorax, the stripe is somewhat lighter in color having a distinct reddish tinge. The posterior angles of all the abdominal segments above, except the last three, are distinctly flecked with pure white. There is also a somewhat indefinite white spot on each side of the dorsal stripe on each side segment. The appearance of the ventral side of the insect is the same by reflected as by transmitted light.

Larva. - On the $23 \mathrm{~d}$ of October, 1903, several specimens, apparently all belonging to the same larval instar, were found congregated together with a number of adults.

Length $\mathrm{I} .2 \mathrm{~mm}$; ; width of meso-thorax $.36 \mathrm{~mm}$. General shape fusiform ; color red.

Head quadrate and lighter in color than body; cheeks straight and parallel; post-ocular bristles prominent and knobbed. The head also bears four other bristles which are similar to those behind the eyes; two of these are situated between the eyes, one on each side, about half-way between the middle of the head and the margin of the eye; the other two are situated about half-way between these and the margin of the thorax. The eyes are small, round, black in color, and very widely separated. Antennae consisting of seven segments, lightbrown in color, the third segment the longest; second segment bearing knobbed hairs, fourth and fifth segments bearing sense cones; apical segment bluntly pointed and bearing a long, slender, acute hair at its end.

Thorax red, with irregular and indefinite transparent markings; bearing knobbed hairs like those on the head on all three segments. Legs very light brown in color; femora bearing knobbed hairs; tarsi bearing two strong claws.

Abdomen about one-half the length of the body, tapering gradually to the end of the tube; red in color, with irregular transparent markings; first segment transparent, fourth segment somewhat lighter than the others. All the segments, except the last two, bear knobbed hairs. Toward the posterior part of the abdomen, the hairs gradually grow longer. Around the posterior margin of the gth segment there is a circlet of long spines which are strongly bent near their tips. The tube is about two thirds the length of the head, tapers gradually from base to apex, is light brown in color, and bears a circlet of acutely pointed spines at its tip; only two of the eight extremely long hairs seen in the adult are developed and these are on the ventral side of the tube in all my specimens.

On October 3 rd, 1903, I found a large female Acanthothrips nodicornis Reut. also under the burk of the sycamore. This is the species on which Uzel founded the genus and it does not seem to have been reported heretofore in this country.

It would be useless for one to attempt to redescribe the species from one specimen, but this species may be readily distinguished from magnafemoralis by its larger size and dark brown color. The last three abdominal segments are dark 
brown and the tube does not bear a circlet of eight very long hairs as in magnafemoralis. There is a very distinct white fleck, seen by reflected light, on the anterior corners of all the abdominal segments above, except the two basal and the two apical. Uzel gives the average length of the females of the species as being $2.4 \mathrm{~mm}$. My specimen is a very large one measuring about $3 \mathrm{~mm}$. in length.

The foregoing studies were made at the Entomological laboratory of the Massachusetts agricultural college. 

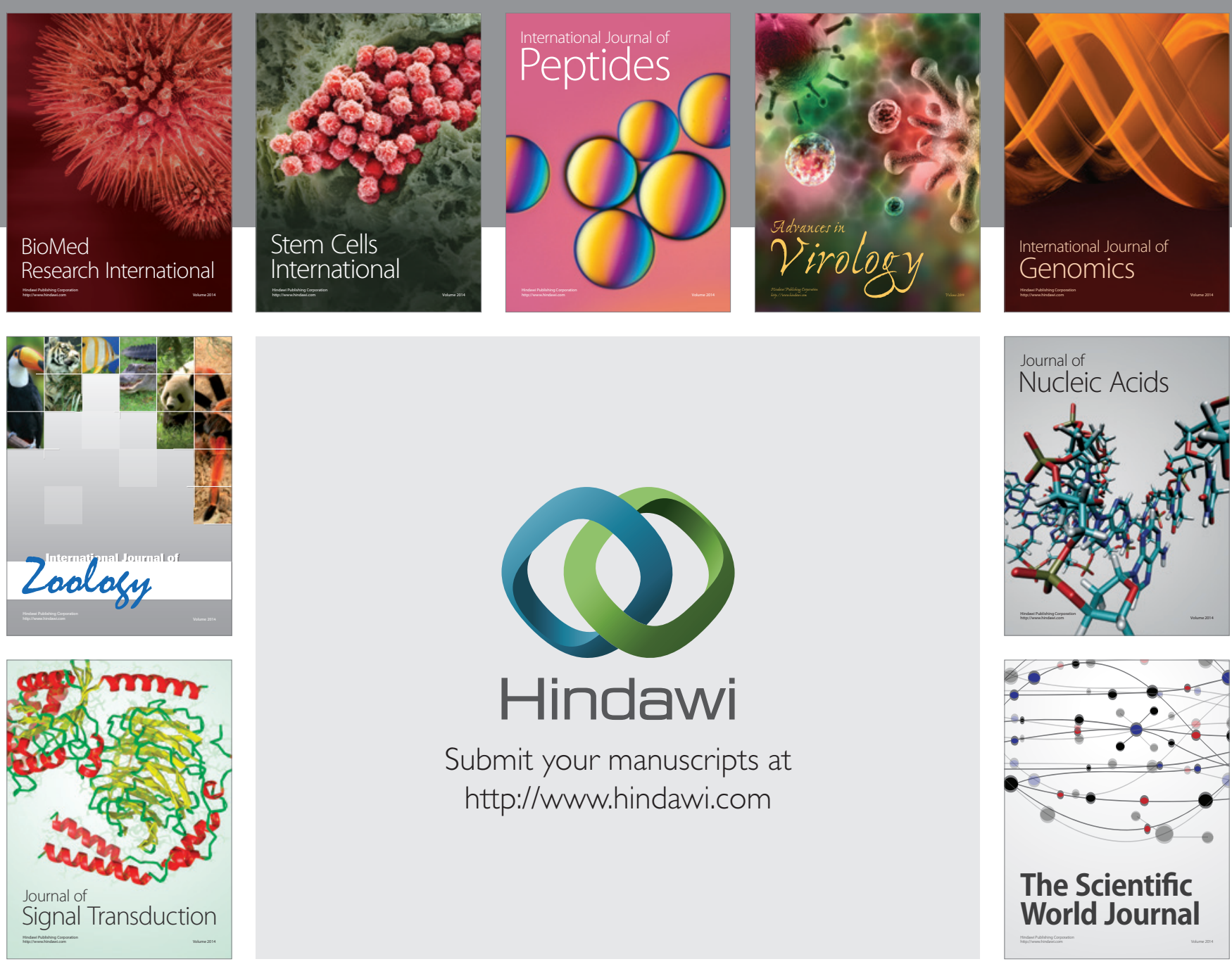

Submit your manuscripts at

http://www.hindawi.com
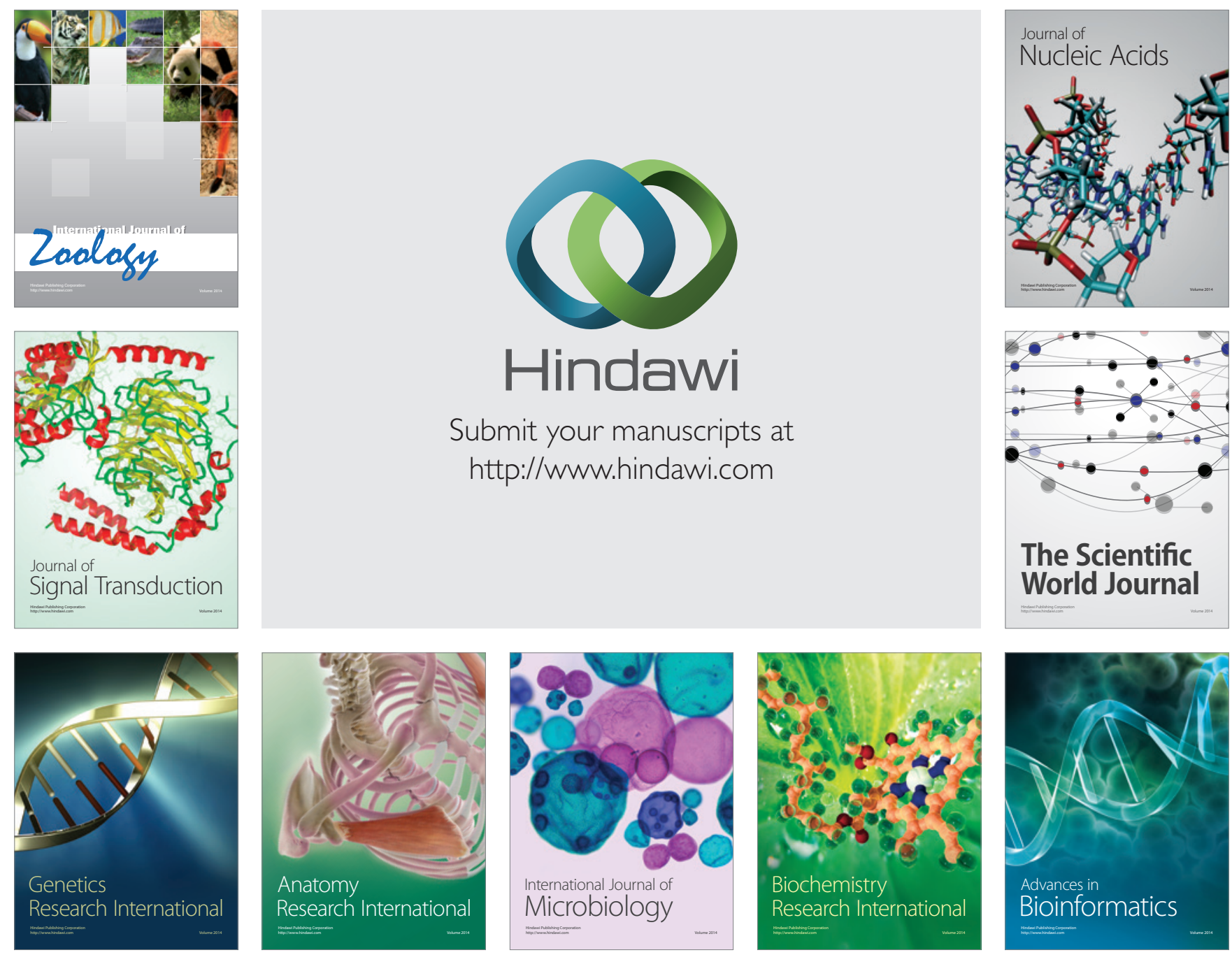

The Scientific World Journal
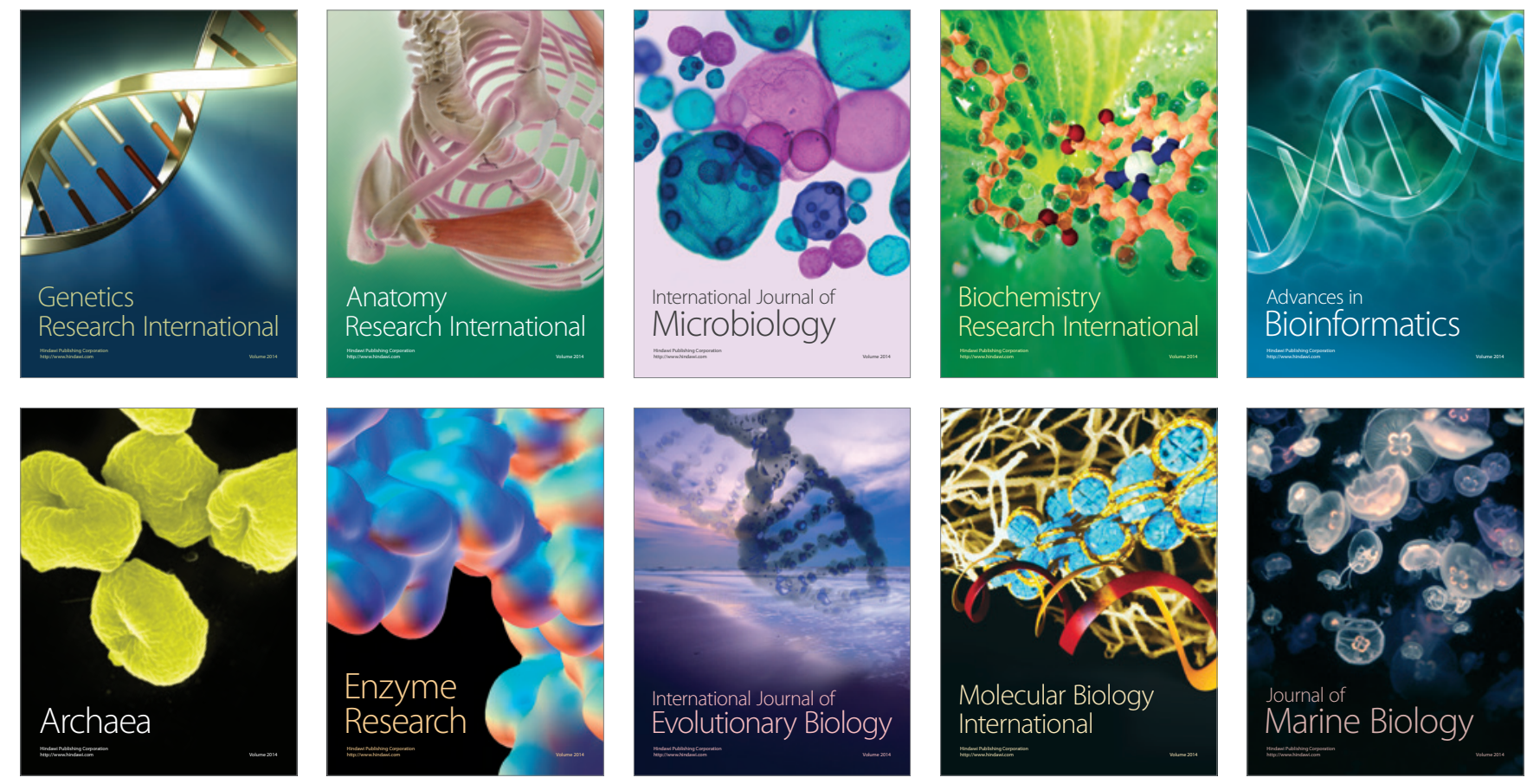